\section{Community paediatrics and child health}

To the Editor: In 2012, the Postgraduate Education Committee of the Health Professions Council of South Africa (HPCSA) supported the accreditation of Community Paediatrics and Child Health $(\mathrm{CPCH})$ as a paediatric subspecialty; however, full HPCSA approval is outstanding. Consequently, by February 2015 there had been no visible progress towards implementation. Power and Heese $^{[1]}$ and Swingler et al. ${ }^{[2]}$ highlighted the benefits of $\mathrm{CPCH}$, rendering further debates about $\mathrm{CPCH}$ accreditation unnecessary, particularly in a country where: $(i)$ progress towards the fourth Millennium Development Goal is slow; (ii) glaring gaps exist between hospital-based and community care, and between private and public sector care; ${ }^{[3]}$ and (iii) current under- and postgraduate paediatric training emphasises clinical subspecialties (despite reduced public sector posts), yielding graduates with limited knowledge about priority child health conditions. Primary healthcare re-engineering and the establishment of district clinical specialist teams in South Africa have starkly revealed the urgency of $\mathrm{CPCH}$ training. ${ }^{[4]} \mathrm{CPCH}$ locates child health within a sociocultural-economic-political-environmental-systemic paradigm. ${ }^{[5]}$ Successful community paediatricians share four characteristics: ${ }^{\left[{ }^{[}\right]}(i)$ academic collaboration; (ii) finding evidencebased local solutions; (iii) establishing strong community-based partnerships; and (iv) addressing disease outside traditional biomedical models. This suggests that our sometimes narrow approach to under- and postgraduate training needs significant adaptation. The British Association for Community Child Health, affiliated to the Royal College of Paediatricians, is a successful model we can adapt. ${ }^{[7]}$ This custodian of community paediatrics directs traineeships, stipulates requirements and outlines the scope of the discipline.

We suggest six actions to facilitate progress:

1. Approval of $\mathrm{CPCH}$ as a subspecialty

2. Advocacy for $\mathrm{CPCH}$ and community paediatricians to create a demand at medical schools and among users in the community

3. Establishment of a pool of $\mathrm{CPCH}$ experts at medical schools to facilitate training in community paediatrics

4. A compulsory rotation in $\mathrm{CPCH}$ for all undergraduate medical students

5. Development of accredited training sites and posts for paediatricians wanting to subspecialise in $\mathrm{CPCH}$

6. Revision of the paediatric registrar rotation to include a compulsory 6-month regional hospital or similar $\mathrm{CPCH}$ rotation.

The examples set by the University of the Witwatersrand (Community Paediatrics Division) and the University of Cape Town (School of Child and Adolescent Health, Postgraduate Diploma in Community and General Paediatrics) should inspire the launch of similar programmes in other medical schools.

Unless community paediatric training is rapidly expanded and resourced, our current health policies will remain mere statements.

Where is the block, and can we be proactive?

\section{Ameena E Goga}

Health Systems Research Unit, South African Medical Research Council, Cape Town South Africa, and Department of Paediatrics, School of Medicine, Faculty of Health Sciences, University of Pretoria, South Africa

ameena.goga@mrc.ac.za

\section{Ute Feucht}

Department of Paediatrics, School of Medicine, Faculty of Health Sciences,

University of Pretoria, South Africa, and Tshwane District Clinical Specialist Team, Gauteng Department of Health, Johannesburg, South Africa

\section{Michael Hendricks}

\section{Anthony Westwood}

School of Child and Adolescent Health, Faculty of Health Sciences,

University of Cape Town, South Africa

\section{Haroon Saloojee}

Division of Community Paediatrics, Department of Paediatrics and Child Health, Faculty of Health Sciences, University of the Witwatersrand, Johannesburg, South Africa

\section{George Swingler}

School of Child and Adolescent Health, Faculty of Health Sciences,

University of Cape Town, South Africa

\section{Neil McKerrow}

Department of Paediatrics and Child Health, Nelson R Mandela School of Medicine, College of Health Sciences, University of KwaZulu-Natal, Durban, South Africa, and Department of Health, KwaZulu-Natal

\section{David Sanders}

School of Child and Adolescent Health, Faculty of Health Sciences, University of Cape Town, South Africa, and School of Public Health, University of the Western Cape, Bellville, Cape Town

\footnotetext{
1. Power DJ, Heese HdeV. The role of community paediatrics in South Africa. S Afr Med J 1978;53(3):408-410 2. Swingler G, Hendricks M, Hall D, et al. Can a new paediatric sub-specialty improve child health in South Africa? S Afr Med J 2012;102(9):738-739. [http://dx.doi.org/10.7196/SAMJ.5714]

Mayosi BM. Benatar SR. Health and health care in South Africa - 20 years after Mandela. N Engl J Med 3. Mayosi BM. Benatar SR. Health and health care in South Africa -20 ye
2014;371(14):1344-1353. [http://dx.doi.org/10.1056/NEJMsr1405012]

4. District Clinical Specialist Teams in South Africa: Ministerial Task Team Report to the Honourable Minister 4. District Clinical Specialist Teams in South Africa: Ministerial Task Team Report to the Honourable Minister
of Health, Dr Aaron Motsoaledi. http://www.rmchsa.org/wp-content/resources/resources_by_type/ of Health, $\mathrm{Dr}$ Aaron Motsoaledi. http://www.rmchsa.org/wp-content/resources/resources_by_typ
DistrictLevelResources/MinisterialTTReport_DCSTInSouthAfrica.pdf (accessed 20 February 2015). 5. Council on Community Pediatrics. Community pediatrics: Navigating the intersection of medicine 5. Council on Community Pediatrics. Community pediatrics: Navigating the intersection of medicine,
public health, and social determinants of children's health. Pediatrics 2013:131(3):623-628. [http:// dx.doi.org/10.1542/peds.2012-3933]

6. Sanders L, Robinson T, Forster L, Plax K, Brosco J, Brito A. Evidence-based community pediatrics: Building a bridge from bedside to neighbourhood. Pediatrics 2005;115(4):1142-1147. [http://dx.doi. org/10.1542/peds.2004-2825H

7. British Association for Community Child Health. Community child health and the future: A BACCH discussion paper. February 2005. http://www.bacch.org.uk/downloads/briefing_papers/community_ child_health_future.pdf (accessed 9 February 2015).
}

\section{S Afr Med J 2015;105(4):243. DOI:10.7196/SAMJ.955}

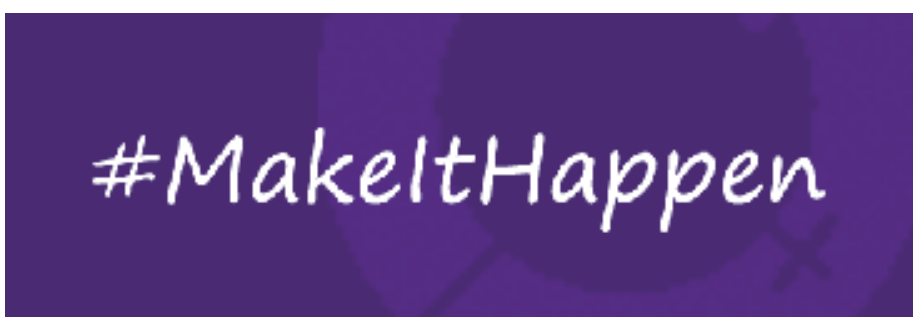

International Women's Day 2015 Theme: MAKE IT HAPPEN All around the world, International Women's Day represents an opportunity to celebrate the achievements of women while calling for greater equality.

International Women's Day (IWD) was celebrated on 8 March. The first International Women's Day was held in 1911. 